\title{
ATMOSFERA MODIFICADA E TEMPERATURA DE ARMAZENAMENTO PARA PÓS-COLHEITA DE AMEIXA DA MATA
}

Juliana Cristina Radaelli, Kelli Pirola, Marcelo Dotto, Américo Wagner Júnior, Idemir Citadin, Luciano Lucchetta

Universidade Tecnológica Federal do Paraná - UTFPR, Programa de Pós-Graduação em Agrossistemas, PR. E-mail: julianaradaelli@gmail.com

\section{RESUMO}

O objetivo deste trabalho foi avaliar o efeito da atmosfera modificada e temperatura de armazenamento na conservação pós-colheita de ameixa da mata. Foram conduzidos dois experimentos, ambos em delineamento inteiramente casualizado com 4 repetições de 20 frutos. O primeiro em fatorial 2x3 (embalagem $x$ temperatura), onde os frutos foram acondicionados em bandejas de poliestireno revestidas ou não por filme de PVC, em condições de temperatura ambiente $\left(21,8{ }^{\circ} \mathrm{C}\right.$ e $71 \%$ UR $), 5 \pm 1{ }^{\circ} \mathrm{C}$ ou $15 \pm 1{ }^{\circ} \mathrm{C}$. No segundo, em fatorial $2 \times 3 \times 2$ (pedúnculo $x$ embalagem $x$ temperatura). Para o fator pedúnculo foi considerada a presença ou ausência nos frutos, sendo estes acondicionados em bandejas de poliestireno com e sem filme de PVC ou com biofilme (fécula de mandioca) e armazenados em duas temperaturas ambiente $\left(21,8{ }^{\circ} \mathrm{C}\right.$ e $71 \%$ UR) e $5 \pm 1{ }^{\circ} \mathrm{C}$. Foram avaliados a perda de massa fresca, murchamento, podridão, teor de sólidos solúveis, açúcares totais e redutores, teores de antocianinas e flavonoides. O uso de atmosfera modificada com uso de filme de PVC associada à temperatura de $5{ }^{\circ} \mathrm{C}$, permitiu armazenar frutos de ameixeira da mata por período de até 34 dias. Sugere-se manter o pedúnculo aderido ao fruto, pois estes mantiveram a qualidade e a aparência por mais tempo, além de conservarem as características bioquímicas dos frutos como açúcares totais e redutores e a manutenção dos teores de antocianinas e flavonoides nos frutos.

Palavras-chave: Eugenia candolleana; Myrtaceae; frutas nativas.

\section{MODIFIED ATMOSPHERE AND STORAGE TEMPERATURE FOR AMEIXA DA MATA POST-HARVEST}

\begin{abstract}
The aim of this work was to evaluate the effect of modified atmosphere and temperature in the ameixa da mata fruit post-harvest conservation. Two experiments were carried out in design completely randomized, with 4 replications of 20 fruits by plot. The first was used in the factorial desing $2 \times 3$ (package $\times$ temperature), with the fruits packed in polystyrene trays covered or not by PVC film. The temperature conditions used were atmosphere normal $\left(21,8{ }^{\circ} \mathrm{C}\right.$ e $71 \%$ UR), $5 \pm 1{ }^{\circ} \mathrm{C}$ and $15 \pm 1{ }^{\circ} \mathrm{C}$. In the second, it was used in a factorial design $2 \times 3$ $\times 2$ (peduncle $x$ package $x$ temperature). In the peduncle factor was considered its presence or absence in the fruits, which are packed in trays of polystyrene with and without PVC film or with biofilms (cassava starch), it being stored at two temperatures normal $\left(21,8{ }^{\circ} \mathrm{C}\right.$ e $71 \%$ UR) and $5 \pm 1{ }^{\circ} \mathrm{C}$. The mass fresh loss, wilting, rot, soluble solids, total and reducing sugars, anthocyanins and flavonoids were evaluated. The use of modified atmosphere associated with temperature of $5{ }^{\circ} \mathrm{C}$ allowed to store ameixa da mata fruit native during 34 days. It was recommended to keep the peduncle in the fruit, because they maintained the quality and the appearance by time, besides maintaining like biochemical of the fruits like sugars and reducers and the maintenance of the anthocyanins and flavonoid contents in the fruits.
\end{abstract}

Keywords: Eugenia candolleana; Myrtaceae; native fruit. 


\section{INTRODUÇÃO}

A ameixeira da mata (Eugenia candolleana) é fruteira nativa, pertencente à família Myrtaceae, sendo praticamente desconhecida pela maioria da população. Esta espécie pode ser encontrada desde a mata pluvial Atlântica do Rio de Janeiro e Espírito Santo e, da Zona da Mata de Minas Gerais até o Sul do País (LORENZI et al., 2006).

Morfologicamente, a planta é caducifólia, com altura entre 4 e 7 metros, produzindo frutos pretos, brilhantes, globosos ou oblongos, com polpa espessa, carnoso-suculenta, firme, de sabor doce muito agradável, cuja maturação coincide nos meses de fevereiro e março (LORENZI et al., 2006), o que a torna interessante, pois é época de pouca oferta de frutos no mercado.

A ameixa da mata é fruta que possue baixa longevidade do período pós-colheita. Para manter maior período pós-colheita, técnicas para aumentar a conservação de frutos, podem ser utilizadas como a redução de $\mathrm{O}_{2}$ e aumento do $\mathrm{CO}_{2}$, através da atmosfera modificada e baixa temperatura, bem como aplicação de radiação ionizante gama ou ultravioleta além de tratamento térmico (BRACKMANN et al., 2012).

Por isso, a utilização de atmosfera modificada, por meio de filmes plásticos ou biofilmes auxiliam na manutenção da qualidade dos frutos já que possuem a função de diminuir os níveis de $\mathrm{O}_{2}$ e o aumento da concentração de $\mathrm{CO}_{2} \mathrm{O}$ que consequentemente reduz a taxa de respiração, a produção de etileno, a redução da perda de água já que atuam na degradação dos frutos, diminuindo a sua viabilidade (CHITARRA; CHITARRA, 2005; SOARES et al., 2012). Quando associada a refrigeração, o período pós-colheita, pode ser prolongado, já que temperaturas inferiores a $10{ }^{\circ} \mathrm{C}$ auxiliam na redução da taxa respiratória e com ela a perda de sabor, cor, textura e várias características de qualidade dos frutos (CHITARRA; CHITARRA, 2005).

O objetivo deste trabalho foi avaliar o efeito da atmosfera modificada e temperatura de armazenamento na conservação pós-colheita de ameixa da mata.

\section{MATERIAL E MÉTODOS}

Foram conduzidos dois experimentos, no Laboratório de Fisiologia Vegetal, da Universidade Tecnológica Federal do Paraná - Câmpus Dois
Vizinhos, PR. Os frutos maduros de ameixeira da mata (E. candolleana DC.), com coloração predominante violácea, de duas plantas matrizes da referida instituição, foram colhidos manualmente com o auxílio de tesouras. No Laboratório realizou-se a seleção dos frutos, mantendo-os com o mesmo padrão de maturação e sem a presença de qualquer tipo de dano aparente.

Para o primeiro experimento, o delineamento adotado foi inteiramente casualizado em esquema fatorial $2 \times 3$ (embalagem $x$ temperatura de conservação), com 4 repetições de 20 frutos. No fator embalagem, todos frutos foram acondicionados em bandejas de poliestireno $(12 \mathrm{x}$ $12 \times 2,5 \mathrm{~cm})$, diferindo-se apenas pelo revestimento ou não de filme plástico de policloreto de vinila (PVC, 10 micras). Em seguida, as embalagens com os frutos foram armazenadas em três condições de temperatura [ambiente $(21,8$ ${ }^{\circ} \mathrm{C}$ e $71 \%$ UR), $5 \pm 1{ }^{\circ} \mathrm{C}$ e $15 \pm 1{ }^{\circ} \mathrm{C}$ ], em B.O.D.

No segundo, o delineamento utilizado foi inteiramente casualizado em fatorial $2 \times 3 \times 2$ (pedúnculo $x$ embalagem $x$ temperatura de conservação), com 4 repetições de 20 frutos. Para o fator pedúnculo, após a colheita manual, os frutos foram separados em dois lotes, sendo que no primeiro foi mantido o pedúnculo ligado ao fruto e no segundo o mesmo foi retirado. No fator embalagem, os frutos foram colocados em bandejas de poliestireno $(12 \times 12 \times 2,5 \mathrm{~cm})$, sendo então recobertos ou não por filme plástico de PVC usado no experimento 1 ou recobertos com biofilme a base de fécula de mandioca [ $6 \%$, (100 $\mathrm{mL}$ de água destilada e $0,6 \mathrm{~g}$ de fécula de mandioca)] em sua epiderme. Os frutos então foram armazenamento em duas condições de temperatura, sendo ambiente $\left(21,8{ }^{\circ} \mathrm{C}\right.$ e $71 \%$ UR) e controlada $\left(5 \pm 1{ }^{\circ} \mathrm{C}\right)$.

Em ambos os experimentos, as avaliações físicas e químicas foram realizadas em relação à qualidade do fruto, como a perda de massa fresca (\%) por meio da pesagem dos frutos em balança semi analítica (marca: BEL, modelo: 3502 ) no início ao final do tempo de armazenamento.

O murchamento e a podridão dos frutos foram analisados através da observação dos frutos afetados. Em relação ao murchamento avaliou-se a porcentagem de frutos que apresentaram depressões na epiderme em relação ao total de 
frutos em cada repetição. Da mesma forma para a podridão foi observada a porcentagem de frutos que apresentaram presença ou não de sintomas de infecção por patógenos (formação de estruturas dos fungos).

O teor de sólidos solúveis totais (SST) expresso em ${ }^{\circ}$ Brix, foi determinado por meio de refratômetro digital (marca: Digital Refractometer, modelo: RTD-95) segundo a metodologia descrita por AOAC (2012).

Para a determinação das concentrações de açúcares totais utilizou-se o método fenolsulfúrico, descrito por Dubois et al. (1956). A leitura das amostras foi realizada a $490 \mathrm{~nm}$ em espectrofotômetro. Para açúcares redutores, o método utilizado foi de dinitrosalicilato (DNS) descrito por Miller (1959). A leitura das amostras foi realizada em espectrofotômetro a $540 \mathrm{~nm}$. As concentrações de açúcares totais e redutores foram calculados em função da curva padrão de glicose, e os resultados expressos em mg g tecido ${ }^{-1}$.

Os teores de antocianinas e flavonoides foram determinados através do preparo de extrato contendo $1 \mathrm{~g}$ de material vegetal e $25 \mathrm{~mL}$ de solução extratora composta de etanol a $95 \%$ e HCl $1,5 \mathrm{~N}$, na proporção 85:15 (v/v) segundo a metodologia de Lees e Francis (1972). A leitura das amostras de flavonoides foi realizada a $374 \mathrm{~nm}$ e para antocianinas a $535 \mathrm{~nm}$ em espectrofotômetro.
Os valores foram expressos em mg $100 \mathrm{~g}^{-1}$ de material vegetal, respectivamente.

Os dados obtidos em ambos experimentos, foram submetidos ao teste de normalidade de Lilliefors e posteriormente a análise da variância, com as médias comparadas entre si pelo teste de Duncan $(\alpha=0,05)$. No primeiro experimento, somente para variável açúcares totais não houve transformação de dados e para o experimento 2, com a variável sólidos solúveis totais. As demais variáveis foram transformadas em arco seno $\checkmark x / 100$ para dados expressos em porcentagem e $\sqrt{ } \mathrm{x}+1$, para os de números inteiros. Para a realização destas análises foram utilizados os programas GENES para o teste de normalidade e o SANEST para as demais análises.

\section{RESULTADOS E DISCUSSÃO}

Em relação a utilização da atmosfera modificada, por meio de filmes de PVC associada a temperatura de armazenamento, houve interação significativa entre os fatores utilizados no Experimento 1.

Os frutos de ameixeira da mata mantiveram-se viáveis para consumo por 34 dias, quando utilizado filme de PVC e temperatura de 5 ${ }^{\circ} \mathrm{C}$, com perda de massa de 8,98\% (Tabela 1 ).

Tabela 1. Perda de massa fresca (\%) em ameixa da mata após armazenamento em diferentes temperaturas e atmosfera modificada.

\begin{tabular}{|c|c|c|}
\hline \multirow[t]{2}{*}{ Temperatura } & \multicolumn{2}{|c|}{ Embalagem } \\
\hline & Com filme PVC & Sem filme PVC \\
\hline $5^{\circ} \mathrm{C}$ & 8,98 a B & $19,40 \mathrm{~b} \mathrm{~A}$ \\
\hline $15^{\circ} \mathrm{C}$ & $2,63 \mathrm{~b} \mathrm{~B}$ & $22,32 \mathrm{~b} \mathrm{~A}$ \\
\hline Ambiente & 8,32 a $B$ & 43,78 a A \\
\hline
\end{tabular}

*Médias com letras diferentes, minúscula na mesma coluna e maiúsculas na mesma linha, diferem significativamente ao nível de $5 \%$ de probabilidade pelo teste de Duncan.

Na mesma condição de temperatura $\left(5^{\circ} \mathrm{C}\right)$, mas sem a utilização do filme de PVC, os frutos mantiveram aparência por apenas 12 dias observando perda de massa de 19,40\% Quando armazenados a $15^{\circ} \mathrm{C}$ e a temperatura ambiente ( 21 $\left.{ }^{\circ} \mathrm{C}\right)$, o tempo de armazenamento limitou-se a 9 dias observando perda de massa de $2,63 \%$ e $43,78 \%$, respectivamente (Tabela 1 ).
Ao ser avaliada a porcentagem de perda de massa fresca (Tabela 1), verificou-se que o uso de bandejas de poliestireno revestidas com plástico PVC, reduziu a perda de água dos frutos. Esta característica é desejável, pois mantém sua suculência por não haver a perda de água.

Oliveira et al (2014) avaliaram a qualidade pós-colheita de camu-camu (Myrciaria dubia), 
através da refrigeração e o uso de filmes plásticos de PVC, BOPP (polipropileno biaxialmente orientado) com espessura de $50 \mu \mathrm{m}$ e frutos sem embalagem, em temperatura de $5 \pm 1^{\circ} \mathrm{C}$ e $90 \pm 2 \%$ de umidade relativa. $\mathrm{O}$ uso de filmes de $\mathrm{PVC}$, reduziu a perda de massa dos frutos de camu-camu, mantendo-se a qualidade por 21 dias. Para as demais variáveis $\mathrm{pH}$, sólidos solúveis, acidez titulável, ácido ascórbico e antocianinas os tipos de filmes utilizados, não tiveram influência sobre as mesmas.

Em relação a aparência dos frutos, estes não apresentaram murchamento e podridão aparente (Tabela 2 ), durante o período avaliado.

Tabela 2. Aparência [murchamento e podridão (\%)] em ameixa da mata após armazenamento em diferentes temperaturas e atmosfera modificada.

\begin{tabular}{|c|c|c|}
\hline \multirow{3}{*}{ Temperatura } & \multicolumn{2}{|c|}{ Embalagem } \\
\hline & \multicolumn{2}{|c|}{ Murchamento (\%) } \\
\hline & Com filme PVC & Sem filme PVC \\
\hline $5^{\circ} \mathrm{C}$ & 0,00 c B & $45,08 \mathrm{~b} \mathrm{~A}$ \\
\hline $15^{\circ} \mathrm{C}$ & 14,64 b B & 100,00 a $A$ \\
\hline Ambiente & 44,86 a B & 100,00 a $A$ \\
\hline \multirow[t]{3}{*}{ CV (\%) } & \multicolumn{2}{|c|}{3,42} \\
\hline & \multicolumn{2}{|c|}{ Podridão (\%) } \\
\hline & Com filme PVC & Sem filme PVC \\
\hline $5^{\circ} \mathrm{C}$ & 0,00 c A* $^{*}$ & 0,00 a $A$ \\
\hline $15^{\circ} \mathrm{C}$ & $4,65 \mathrm{~b} \mathrm{~A}$ & 0,32 a $B$ \\
\hline Ambiente & 43,47 a $A$ & 0,00 a B \\
\hline CV (\%) & & \\
\hline
\end{tabular}

*Médias com letras diferentes, minúscula na mesma coluna e maiúsculas na mesma linha, diferem significativamente ao nível de $5 \%$ de probabilidade pelo teste de Duncan.

Observou-se que os frutos submetidos a temperatura ambiente e de $15{ }^{\circ} \mathrm{C}$, apresentaram frutos $100 \%$ murchos, já que estes não estavam em condição de atmosfera modificada, mesmo efeito não foi observado na temperatura de $5{ }^{\circ} \mathrm{C}$ (Tabela 2). A baixa temperatura $\left(5{ }^{\circ} \mathrm{C}\right)$ favorece a manutenção da qualidade dos frutos, principalmente com a associação da atmosfera modificada reduzindo a perda de água e a incidência de patógenos.

Estes resultados demonstraram as vantagens da utilização de filme plástico, para a manutenção da aparência de fruto, uma vez que atua reduzindo as trocas gasosas no interior da embalagem e o ambiente externo, com reflexo na menor perda de água e consequentemente o murchamento. Para os aspectos relacionados a aparência dos frutos avaliados pode-se observar que o aumento da temperatura e a ausência do revestimento favoreceu maiores perdas de qualidade nos frutos de ameixeira da mata.
Rinaldi et al. (2017) ao avaliarem a vida útil pós-colheita de frutos de maracujazeiro azedo, submetidos a refrigeração, observaram que após quatro dias de armazenamento houve perda de massa, apresentando enrugamento da casca.

Por outro lado, a podridão apresentou maior incidência com o emprego da atmosfera modificada e da temperatura ambiente, devido a formação de microclima favorável a proliferação de fungos, permitindo $o$ estabelecimento e disseminação dos esporos fúngicos que até então estavam latentes. Nos tratamentos com temperaturas de 5 e $15{ }^{\circ} \mathrm{C}$, não houve $\mathrm{o}$ desenvolvimento de podridões decorrentes de infecções latentes ou pelo processo de senescência dos frutos pelo ambiente não ser favorável.

Para o teor de sólidos solúveis totais (SST) (Tabela 3), observou-se que os frutos das bandejas não revestidas com filme de PVC e mantidas em temperatura ambiente $\left(21,8^{\circ} \mathrm{C}\right.$ e $71 \%$ UR) e de 15 ${ }^{\circ} \mathrm{C}$ o teor de SST foram superiores aqueles mantidos em bandejas revestidas com PVC, sendo de 22,58 
${ }^{\circ}$ Brix e $19,28^{\circ}$ Brix, respectivamente. Porém, o uso ou não do filme de PVC não diferiu estatisticamente quando os frutos foram armazenados em temperatura de $5^{\circ} \mathrm{C}$.

Tabela 3. Teor de sólidos solúveis totais ( ${ }^{\circ}$ Brix) e teor de açúcar redutor ( $m g$ g tecido ${ }^{-1}$ ) em ameixa da mata após armazenamento em diferentes temperaturas e atmosfera modificada.

\begin{tabular}{|c|c|c|}
\hline \multirow{3}{*}{ Temperatura } & \multicolumn{2}{|c|}{ Embalagem } \\
\hline & \multicolumn{2}{|c|}{ SST ( ${ }^{\circ}$ Brix) } \\
\hline & Com filme PVC & Sem filme PVC \\
\hline $5^{\circ} \mathrm{C}$ & 17,61 a $A^{*}$ & 17,92 b A \\
\hline $15^{\circ} \mathrm{C}$ & 12,69 b B & 19,28 b A \\
\hline Ambiente & 14,54 b B & 22,58 a $A$ \\
\hline \multirow[t]{3}{*}{ CV (\%) } & \multicolumn{2}{|c|}{5,01} \\
\hline & \multicolumn{2}{|c|}{ Açúcar Redutor (mg g tecido-1 ${ }^{-1}$} \\
\hline & Com filme PVC & Sem filme PVC \\
\hline $5^{\circ} \mathrm{C}$ & $0,065^{\mathrm{ns}}$ & $0,060^{\text {ns }}$ \\
\hline $15^{\circ} \mathrm{C}$ & $0,062^{\text {ns }}$ & $0,062^{\mathrm{ns}}$ \\
\hline Ambiente & $0,067^{\text {ns }}$ & $0,060^{\text {ns }}$ \\
\hline CV (\%) & & \\
\hline
\end{tabular}

Os teores de SST presentes nos frutos são importantes tanto para o consumo in natura como para indústria, sendo utilizados como critério de avaliação do "flavor", juntamente com sua acidez (CHITARRA; CHITARRA, 2005).

Quando aplicada a atmosfera modificada associada a baixas temperaturas, o teor de sólidos solúveis foi maior que as demais temperaturas. Acredita-se que nesta condição o metabolismo tenha sido reduzido se comparado a temperatura de $15{ }^{\circ} \mathrm{C}$ e de ambiente natural, fazendo com que houvesse menor consumo do açúcar de reserva, prolongando seu tempo de prateleira.

O uso de filmes plásticos ou coberturas, formam barreiras semipermeáveis que impedem ou inibem a migração de umidade, oxigênio, dióxido de carbono, lipídios, aromas, dentre outros (SANTO; ALBUQUERQUE, 2015). Além disso, o uso da atmosfera modificada auxilia na manutenção de teores de SST menores. $\mathrm{O}$ fato da temperatura de armazenamento a $5 \quad{ }^{\circ} \mathrm{C}$ ter igualado estatisticamente deve-se pela menor atividade metabólica que os frutos apresentaram, independente do uso de PVC como embalagem.

$\mathrm{Na}$ avaliação dos açúcares redutores não houve diferença estatística $(p<0,05)$ entre a utilização ou não da atmosfera modificada, bem como para as diferentes temperaturas de armazenamento (Tabela 3).

Carneiro et al. (2015), avaliaram os teores de açúcar solúvel total (AST) em que os fruto de cagaita (Eugenia dysenterica DC.) mantidos em refrigeração $\left(5^{\circ} \mathrm{C}\right)$ com e sem revestimento de PVC, teve aumento após 4 e 5 dias de armazenamento. Para a quantidade de açúcares redutores, os frutos tiveram redução na sua quantidade de $80 \%$ para frutos armazenados em temperatura de $25{ }^{\circ} \mathrm{C}$ sem PVC. Para os frutos submetidos a temperatura de 5 ${ }^{\circ} \mathrm{C}$ com PVC em $36 \%$.

Para os açúcares totais houve efeito significativo para o fator embalagem (Tabela 4), tendo $25,65 \mathrm{mg} \mathrm{g}$ tecido $^{-1}$ para os frutos acondicionados sem uso de filme PVC,enquanto que, para os frutos submetidos a atmosfera modificada o teor de açúcares foi igual a 23,91 mg $\mathrm{g}$ tecido $^{-1}$. Esse resultado pode ser considerado ideal para conservação da ameixa da mata em prateleira, já que houve baixa variação das concentrações de açúcares, o que pode auxiliar na manutenção da qualidade dos frutos e na maior aceitabilidade pelo consumidor, conforme já descrito por Chitarra e Chitarra (2005). 
Tabela 4. Teor de açúcar total $\left(\mathrm{mg} \mathrm{g}\right.$ tecido $^{-1}$ ) em ameixa da mata após armazenamento em diferentes temperaturas e atmosfera modificada.

\begin{tabular}{lccc}
\hline & \multicolumn{3}{c}{ Embalagem } \\
\cline { 2 - 4 } & Com filme PVC & Sem filme PVC \\
\hline Açúcar Total & $23,91 \mathrm{~b}^{*}$ & 25,65 a \\
\hline CV (\%) & & 4,61 & \\
\hline
\end{tabular}

*Médias com letras diferentes minúscula na mesma linha, diferem significativamente ao nível de $5 \%$ de probabilidade pelo teste de Duncan.

O teor de flavonoides e antocianinas foi de 298,20 e $341,98 \mathrm{mg} 100 \mathrm{~g}^{-1}$ para frutos mantidos em bandejas revestidas com filme de PVC quando fez-se uso de temperatura de $5{ }^{\circ} \mathrm{C}$ para $\mathrm{O}$ armazenamento, respectivamente. Por outro lado, frutos em bandejas sem revestimento apresentaram 373,46 e $290,78 \mathrm{mg} 100 \mathrm{~g}^{-1}$ para ambos compostos, quando do mantidos em condição ambiente $\left(21,8^{\circ} \mathrm{C}\right.$ e $71 \%$ UR) (Tabela 5$)$.

Tabela 5. Teor de flavonoides e antocianinas ( $\mathrm{mg} 100 \mathrm{~g}^{-1}$ ) em ameixa da mata após armazenamento em diferentes temperaturas e atmosfera modificada.

\begin{tabular}{|c|c|c|}
\hline \multirow{3}{*}{ Temperatura } & \multicolumn{2}{|c|}{ Flavonoides } \\
\hline & \multicolumn{2}{|c|}{ Embalagem } \\
\hline & Com filme PVC & Sem filme PVC \\
\hline $5^{\circ} \mathrm{C}$ & 298,20 a $A^{*}$ & 23,45 b B \\
\hline $15^{\circ} \mathrm{C}$ & 30,92 b A & 95,47 b A \\
\hline Ambiente & 88,87 b B & 373,46 a A \\
\hline \multirow[t]{3}{*}{ CV (\%) } & \multicolumn{2}{|c|}{45,23} \\
\hline & \multicolumn{2}{|c|}{ Antocianinas } \\
\hline & Com filme PVC & Sem filme PVC \\
\hline $5^{\circ} \mathrm{C}$ & 341,98 a $A^{*}$ & 190,78 b B \\
\hline $15^{\circ} \mathrm{C}$ & 185,98 b A & 211,61 b A \\
\hline Ambiente & 184,30 b B & 290,78 a A \\
\hline CV (\%) & \multicolumn{2}{|c|}{10,93} \\
\hline
\end{tabular}

*Médias com letras diferentes, minúscula na mesma coluna e maiúsculas na mesma linha, diferem significativamente ao nível de $5 \%$ de probabilidade pelo teste de Duncan.

Na condição ambiente e sem o filme de PVC, os frutos apresentaram maior atividade metabólica resultando na maior síntese destes compostos. Além disso, a maior incidência de podridão ocorreu em frutos acondicionados em bandejas com filme de PVC, que pode ter estimulado a produzir metabólitos secundários para defesa, resultando nos valores de flavonoides e antocianinas obtidos.

No Experimento 2, o maior percentual de perda de massa fresca (Tabela 6) ocorreu em frutos em que houve a manutenção do pedúnculo, nas diferentes temperaturas de armazenamento, porém quando associado ao uso de atmosfera modificada, o uso de filmes de PVC, teve melhores resultados em relação ao uso do biofilme. A temperatura de $5{ }^{\circ} \mathrm{C}$, também contribuiu para a redução a perda de massa dos frutos de ameixeira da mata. O melhor resultado foi na condição de 5 ${ }^{\circ} \mathrm{C}$ com o uso de filme de PVC e a ausência de pedúnculo apresentando perda de massa fresca de $2,77 \%$, já frutos armazenados em condição ambiente $\left(21,8{ }^{\circ} \mathrm{C}\right.$ e $71 \%$ UR) com biofilme e sem qualquer cobertura apresentaram médias de 40,18 e $39,45 \%$ de perda de massa onde o pedúnculo foi mantido, em tratamento em que o mesmo foi retirado, a perda de massa foi de 39,40 e $37,23 \%$ para o uso da atmosfera modificada através de biofilme e sem o qualquer revestimento. 
Tabela 6. Perda de massa fresca (\%) em ameixa da mata após armazenamento em diferentes temperaturas e atmosfera modificada, seguido da presença de pedúnculo.

\begin{tabular}{lllll}
\hline Temperatura & Pedúnculo & \multicolumn{3}{c}{ Embalagem } \\
\hline \multirow{2}{*}{$5^{\circ} \mathrm{C}$} & & Com filme PVC & Sem filme PVC & Com biofilme \\
\cline { 3 - 5 } & Presença & 9,85 a C (a) & 14,71 b B (a) & 17,82 b A (a) \\
\multirow{2}{*}{ Ambiente } & Ausência & 2,77 b B (b) & 16,41 b A (a) & 18,84 b A (a) \\
& Presença & 9,21 a B (a) & 39,45 a A (a) & 40,18 a A (a) \\
& Ausência & 8,36 a B (a) & 37,23 a A (a) & 39,40 a A (a) \\
\hline CV (\%) & & & 4,46 &
\end{tabular}

*Médias seguidas por letras distintas minúsculas na coluna diferem entre si significativamente ao nível de $5 \%$ de probabilidade pelo teste de Duncan, comparando a temperatura dentro de pedúnculo e embalagem. Médias seguidas por letras distintas maiúsculas na linha diferem entre si significativamente ao nível de $5 \%$ de probabilidade pelo teste de Duncan, comparando embalagem dentro de pedúnculo e temperatura. Médias seguidas por letras distintas entre parênteses diferem entre si significativamente ao nível de $5 \%$ de probabilidade pelo teste de Duncan, comparando pedúnculo dentro de embalagem e temperatura.

No estudo desenvolvido por Carneiro et al. (2015), a perda de massa foi maior em frutos armazenados em temperatura de $5{ }^{\circ} \mathrm{C}$ e revestidos por PVC sem perfuração, onde estes frutos tiveram $40 \%$ de perda de massa e 19,2 \% frutos armazenados a $25^{\circ} \mathrm{C}$ com PVC sem perfurações. No presente estudo a ameixa da mata aos 34 dias apresentou 9,85 \% de perda de massa e, em condições semelhantes aos frutos de jabuticabeira. Este é fator importante para conservação da qualidade pós-colheita, já que interfere na aceitabilidade do consumidor.
Analisando a aparência dos frutos se verifica que aqueles mantidos em bandejas sem filme de PVC apresentaram maior ocorrência de murchamento, chegando a incidência de 100\%, seguido pelo uso de biofilme e de filme plástico de PVC. Na condição de armazenamento de $5{ }^{\circ} \mathrm{C}$ e filme de PVC, o murchamento não foi visualizado (Tabela 7). Já para a incidência de frutos podres, não houve sua ocorrência, exceto quando armazenados em temperatura ambiente e com revestimento de filme de PVC.

Tabela 7. Aparência [murchamento e podridão (\%)] em ameixa da mata após armazenamento em diferentes temperaturas e atmosfera modificada.

\begin{tabular}{|c|c|c|c|}
\hline \multirow{3}{*}{ Temperatura } & \multicolumn{3}{|c|}{ Murchamento (\%) } \\
\hline & \multicolumn{3}{|c|}{ Embalagem } \\
\hline & Com filme PVC & Sem filme PVC & Com biofilme \\
\hline $5^{\circ} \mathrm{C}$ & $0,00 \mathrm{~b} \mathrm{C}^{*}$ & 40,37 b A & 15,35 b B \\
\hline Ambiente & 39,71 a B & 100,00 a $A$ & 100,00 a $A$ \\
\hline \multirow[t]{3}{*}{ CV (\%) } & \multicolumn{3}{|c|}{11,86} \\
\hline & \multicolumn{3}{|c|}{ Podridão (\%) } \\
\hline & Com filme PVC & Sem filme PVC & Com biofilme \\
\hline $5^{\circ} \mathrm{C}$ & $0,00 \mathrm{~b} \mathrm{A*}$ & 0,00 a $A$ & 0,00 a $A$ \\
\hline Ambiente & 47,86 a $A$ & 0,00 a B & 0,00 a $B$ \\
\hline CV (\%) & & 39,18 & \\
\hline
\end{tabular}

*Médias com letras diferentes, minúscula na mesma coluna e maiúsculas na mesma linha, diferem significativamente ao nível de $5 \%$ de probabilidade pelo teste de Duncan.

Para que haja murchamento deve-se existir diferenças no potencial hídrico do fruto com o ambiente em que ele se encontra, sendo que este último deve obrigatoriamente ser menor para ocorrência de perdas de água. A temperatura baixa e o filme de PVC proporcionam além da menor 
atividade metabólica, equilíbrio entre os potenciais hídricos o que gera em menor perda de água, conforme pode ser visualizado no presente trabalho.

Coelho et al. (2017) avaliaram o uso de revestimento à base de amido associado ou não ao uso de óleo essencial de cravo-da-índia em goiabas da cultivar 'Pedro Sato' e observaram aumento a vida útil dos frutos em 3 dias, sobre condição ambiente e reduziu a ocorrência incidência de antracnose nos frutos.
Os teores de SST apresentaram maior concentração quando armazenados nas temperaturas de $15{ }^{\circ} \mathrm{C}$ e ambiente $\left(21,8{ }^{\circ} \mathrm{C}\right.$ e $71 \%$ UR) para tratamentos com biofilme e sem revestimento, 24,31 e $24,07^{\circ} \mathrm{Brix}$, respectivamente (Tabela 8). Para temperatura de $5{ }^{\circ} \mathrm{C}$, o uso da atmosfera modificada apresentou teores de 16,44 'Brix para o uso de PVC como recobrimento dos frutos epara frutos com biofilme o teor foi de 17,86 ${ }^{\circ}$ Brix e sem recobrimento de $19,04^{\circ}$ Brix.

Tabela 8. Teor de sólidos solúveis totais ( ${ }^{\circ}$ Brix) em ameixa da mata após armazenamento em diferentes temperaturas e atmosfera modificada.

\begin{tabular}{lccc}
\hline Temperatura & \multicolumn{3}{c}{ Embalagem } \\
\hline & Com filme de PVC & Sem filme de PVC & Com biofilme \\
\cline { 2 - 4 } $5^{\circ} \mathrm{C}$ & 16,44 a A* & $19,04 \mathrm{~b} \mathrm{~A}$ & $17,86 \mathrm{~b} \mathrm{~A}$ \\
Ambiente & 16,19 a B & 24,31 a A & 24,07 a A \\
\hline $\mathrm{CV}(\%)$ & & 13,29 & \\
\hline
\end{tabular}

*Médias com letras diferentes, minúscula na mesma coluna e maiúsculas na mesma linha, diferem significativamente ao nível de $5 \%$ de probabilidade pelo teste de Duncan.

Isso pode ser devido ao fato de que na bandeja com filme de PVC altera-se a relação $\mathrm{O}_{2} / \mathrm{CO}_{2}$, controlando-se assim a atividade metabólica, reduzindo a hidrólise de amido, necessário para formação de SST. O mesmo pode ser considerado na temperatura de $5{ }^{\circ} \mathrm{C}$, o que não alterou o SST dos frutos, independentemente da embalagem testada.

Estes resultados demonstraram que a forma de modificação do ambiente em que se encontram os frutos só tem influência para conservá-los em determinadas temperaturas e que o biofilme permite certa proporção de troca de gases, fato que possibilita a igualdade estatística das médias de SST dos frutos em bandejas sem filme de PVC, gerando maior hidrólise do amido em açúcar simples para fornecer o carbono necessário para a manutenção destes durante o armazenamento.

Para o teor de açúcar total não houve diferença significativa nos tratamentos utilizados. Porém, para os açúcares redutores, houve interação significativa entre as embalagens $x$ temperatura e as embalagens $x$ manutenção ou não do pedúnculo (Tabela 9).

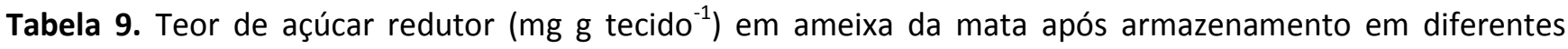
temperaturas e atmosfera modificada, seguido da presença de pedúnculo.

\begin{tabular}{lccc}
\hline & \multicolumn{3}{c}{ Embalagem } \\
\hline $5^{\circ} \mathrm{C}$ & Com filme de PVC & Sem filme de PVC & Com biofilme \\
\cline { 2 - 4 } Ambiente & 0,06 a A* & 0,06 a A & $0,05 \mathrm{~b} \mathrm{~B}$ \\
Presença & 0,06 a A & 0,06 a A & 0,06 a A \\
Ausência & 0,06 a A & 0,06 a A & 0,06 a A \\
\hline CV (\%) & 0,06 a A & 0,06 a A & $0,05 \mathrm{~b} \mathrm{~B}$ \\
\hline
\end{tabular}

*Médias com letras diferentes, minúscula na mesma coluna e maiúsculas na mesma linha, diferem significativamente ao nível de $5 \%$ de probabilidade pelo teste de Duncan. 
Se observou que, na maioria dos níveis de cada interação não houve diferenças estatísticas entre as médias, ocorrendo apenas quando da utilização de biofilme, cujas médias de menor temperatura $\left(5^{\circ} \mathrm{C}\right)$ e ausência de pedúnculo foram menores.

A temperatura ambiente, apresentou valores elevados de flavonoides nos frutos avaliados, sendo que estes foram de 169,39 e $109,51 \mathrm{mg} 100 \mathrm{~g}^{-1}$ para os frutos não revestidos e com biofilme, respectivamente. A presença do pedúnculo, com o filme de PVC, apresentou a maior quantidade de flavonoides, sendo de 87,81 mg $100 \mathrm{~g}^{-1}$ (Tabela 10). Para os teores de antocianinas os teores foram menores para o uso de filme de PVC, na temperatura ambiente, sem filme e biofilme para a temperatura de $5{ }^{\circ} \mathrm{C}$, com valores de 209,66, 141,32 e 120,33 mg $100 \mathrm{~g}^{-1}$, respectivamente. $\mathrm{O}$ uso de filme de PVC, apresentou os maiores teores de antocianinas nos frutos em que houve a manutenção e a retirada do pedúnculo dos frutos, com teores médios de 246,44 e $241,45 \mathrm{mg} 100 \mathrm{~g}^{-1}$, respectivamente.

Tabela 10. Teor de flavonoides e antocianinas (mg $\left.100 \mathrm{~g}^{-1}\right)$ em ameixa da mata após armazenamento em diferentes temperaturas e atmosfera modificada, seguido da presença de pedúnculo.

\begin{tabular}{lccc}
\hline & \multicolumn{3}{c}{ Embalagem } \\
\hline & \multicolumn{3}{c}{ Clavonoides } \\
\cline { 2 - 4 } $5^{\circ} \mathrm{C}$ & Com filme de PVC & Sem filme de PVC & Com biofilme \\
\cline { 2 - 4 } Ambiente & 215,54 a A* & 6,75 b C & 168,79 a B \\
Presença & 17,24 b B & 169,39 a A & 109,51 a A \\
Ausência & 87,81 a A & 39,98 a AB & 34,04 b B \\
\hline CV (\%) & 90,44 a B & 88,02 a B & 166,61 a A \\
\hline & & 33,82 & 120,33 b B \\
$5^{\circ} \mathrm{C}$ & 280,81 a A* & 189,31 a A \\
Ambiente & 209,66 b A & 141,32 b B & 177,22 a B \\
Presença & 246,44 a A & 159,95 a B & 129,80 b B \\
Ausência & 241,45 a A & 167,95 a B & \\
\hline CV (\%) & & 11,86 & \\
\hline
\end{tabular}

*Médias com letras diferentes, minúscula na mesma coluna e maiúsculas na mesma linha, diferem significativamente ao nível de $5 \%$ de probabilidade pelo teste de Duncan.

Em relação ao teor de flavonoides e antocianinas, pode-se observar que quando mantidos em temperatura de $5{ }^{\circ} \mathrm{C}$ e no revestimento das bandejas por meio de filme de PVC os valores foram superiores aos demais. Já para os teores de antocianinas a aplicação dos tratamentos referentes a temperatura de armazenamento não teve diferença significativa dentro de cada uma das embalagens utilizadas.

Moreira et al. (2015) avaliou os teores de antocianinas e flavonoides de romã armazenada em refrigeração e verificaram que a quantidade antocianinas aumentou com o armazenamento nas temperaturas de $6^{\circ} \mathrm{C}, 10^{\circ} \mathrm{C}$ e $12^{\circ} \mathrm{C}$ e os teores de flavonoides reduziram com o tempo de armazenamento. $O$ que não foi observado neste trabalho, pois o adequado armazenamento permitiu maiores teores de antocianinas e flavonoides, já que a biossíntese destes compostos pode continuar durante o armazenamento, mesmo em baixa temperatura.

\section{CONCLUSÃO}

O uso de atmosfera modificada, por meio de filme de PVC associada a temperatura de $5{ }^{\circ} \mathrm{C}$, permitiu conservar os frutos da ameixeira da mata por período de até 34 dias no experimento 1 . Na condição de temperatura de $5{ }^{\circ} \mathrm{C}$ e uso do filme de PVC associada a manutenção do pedúnculo favoreceu a manutenção da qualidade e a aparência por mais tempo, além de conservarem as características bioquímicas. 


\section{REFERÊNCIAS}

AOAC - ASSOCIATION OFFICIAL ANALYTICAL CHEMISTS. Official Methods of Analysis of the Association of Official Analytical Chemistry. 19 ed. Washington, 2012. 3000p

BRACKMANN, A.; ANESE, R. O.; BOTH, V.; THENES, F. R.; FRONZA, D. Atmosfera controlada para armazenamento de goiaba cultivar Paluma. Revista Ceres, v.59, n.2, p.151-156, 2012. http://dx.doi.org/10.1590/s0034737X2012000200001

CARNEIRO, J.O.; SOUZA, M.A.A.; RODRIGUES, Y.J.M.; MAPELI, A.M. Efeito da temperatura e do uso de embalagem na conservação pós-colheita de frutos de cagaita (Eugenia dysenterica DC.). Revista Brasileira de Fruticultura, v.37, n.3, p.568-577, 2015. http://dx.doi.org/10.1590/0100-2945-157/14

CHITARRA, M.I.F.; CHITARRA, A.B. Pós-colheita de frutos e hortaliças: fisiologia e manuseio. 2. ed. Lavras: UFLA, 2005. 320p

COELHO, C.C.S.; FONSECA, M.J.O; SOARES, A.G.; CAMPOS, R.S.; SILVA, O.F. Aplicação de revestimento filmogênico à base de amido de mandioca e de óleo de cravo-da-índia na conservação pós-colheita de goiaba 'Pedro Sato'. Engenharia na Agricultura, v.25, n.6, p. 479-490, 2017

DUBOIS, M.; GILLES, K.A.; HAMILTON, J.K.; REBERS, P.A.; SMITH, F. Colorimetric Method for Determination of Sugars and Related Substances. Analitycal Biochemistry, v.28, p.50-356. 1956.

LEES, D.H.; FRANCIS, F.J. Standardization of pigment analyses in cranberries. HortScience, v.7, n.1, p.83-84, 1972.

LORENZI, H.; SARTORI, S.; BACHER, L.B.; LACERDA, $M$. Frutas brasileiras e exóticas cultivadas: de consumo in natura. São Paulo: Instituto Plantarum de Estudos da Flora, 2006. 640p

MILLER, G.L. Use of dinitrosalicylic and reagent for determination of reducing sugar. Analytical

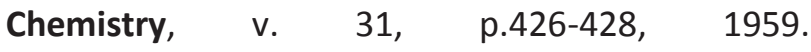
http://dx.doi.org/10.1021/ac60147a030
MOREIRA, I.S.; ROCHA, R.H.C.; PAIVA, E.P.; SILVA, H.S.; SOUSA, F.A. Biometria e componentes físicoquímicos de romã armazenada sob refrigeração. Pesquisa Agropecuária Tropical, v.45, n.2, 2015. http://dx.doi.org/10.1590/1983$\underline{40632015 v 4532501}$

OLIVEIRA, J.; SILVA, I.G.; SILVA, P.P.M.; SPOTO, M.H.F. Atmosfera modificada e refrigeração para conservação pós-colheita de camu-camu. Ciência Rural, v.44, n.6, p.1126-1133, 2014

SANTO, D.C.; ALBUQUERQUE, E.M.B. Principais técnicas pós-colheita para prolongar a vida de frutas e hortaliças. In: OLIVEIRA, E.N.A.; SANTO, D.C. (Org). Tecnologia e processamento de frutos e hortaliças. Natal: IFRN, 2015. 234 p.

RINALDI, M.M.; COSTA, A.M.; FALEIRO, F.G.; JUNQUEIRA, N.T.V. Conservação pós-colheita de frutos de Passiflora setacea DC. submetidos a diferentes sanitizantes e temperaturas de armazenamento. Brazillan Journal of Food Technology, v. 20, e2016046, 2017. http://dx.doi.org/10.1590/1981-6723.4616

SOARES, N.F.F.; CRUZ, R.S.; VILLADIEGO, A.M.D.; MELO, N.R.; SILVEIRA, M.F.A.; BASTOS, M.S.R.; GERALDINE, R.M.; WURLITZER, N.J.; SILVA, W.A.; RODRIGUES, P.P.C.F. Embalagem ativa na conservação de alimentos. In: AZEREDO, H.M.C. Fundamentos da estabilidade de alimentos. Brasília: Embrapa, 2012. 326p

Recebido para publicação em 20/12/2017

Revisado em 29/06/2018

Aceito em 04/07/2018 